\title{
Development of a BIM-based cyber-physical system for facility management of buildings
}

\author{
Alessandro Carbonari ${ }^{\mathrm{a}}$, Leonardo Messi ${ }^{\mathrm{a}, *}$, Berardo Naticchia ${ }^{\mathrm{a}}$, Massimo Vaccarini $^{\mathrm{a}}$, \\ Massimiliano Pirani ${ }^{\mathrm{b}}$ \\ ${ }^{a}$ Polytechnic University of Marche, DICEA, via Brecce Bianche n.12, Ancona, Italy \\ ${ }^{b}$ Polytechnic University of Marche, DII, via Brecce Bianche n.12, Ancona, Italy
}

\begin{abstract}
In the wide facility management context, several processes such as operations, maintenance, retrofitting and renovations ensure that buildings comply with the principles of efficiency and cost-effectiveness. Besides ordinary operation, facility management is responsible for renovation of building facilities and long-term improvement of their performances. In such a scenario, the cyberphysical system (CPS) paradigm with holonic architecture, that will be reported in this paper, can successfully advice the operation management of buildings, as well as long-term refurbishment processes. Indeed and in analogy with the manufacturing field, the developed CPS exploits holons self-configuration and self-organization and overall throughput effectiveness (OTE) metrics, in order to detect the best corrective actions towards system improvements. As a consequence, suggestions and lessons learnt from the evaluation of building efficiency are re-directed to the BIM model. Hence, the digital model acts not only as a repository of currently available equipment for operations management, but also as a repository of the history of the diagnoses that supports decision making during maintenance, retrofitting and renovation processes. As a matter of fact, the repeated detection of a specific issue, since not affected by operations management, should be read as an opportunity to act and enhance the capabilities of buildings components. According to this approach, an automatic real-time diagnosis method is tested in a test case consisting of a multi-use and large public building.
\end{abstract}

(C) 2018 The Authors. Published by Diamond Congress Ltd., Budapest University of Technology and Economics Peer-review under responsibility of the scientific committee of the Creative Construction Conference 2018.

Keywords: BIM; building management system; cyber-physical system; facility management; holonic system.

\section{Introduction}

In the wide facility management context, several processes such as operations, maintenance, retrofitting and renovations ensure that buildings comply with the principles of efficiency and cost-effectiveness. In this field, relevant research is turning towards challenging goal, which can get real benefits from advanced data management and integration of intelligence, so as to produce cause-effect, performance and deterioration modelling, which has not extensively been surveyed, yet [1]. Although preliminary applications concerning performance monitoring have been suggested [2], there is evidence that digitalization and BIM must be further developed to be applied to improved decision making in complex facilities for refurbishment and facility management in general [1]. Furthermore, the importance of BIM in the assessment of the performances of buildings has recently been discussed, along with the possibility of using structured knowledge in order to perform inference about the health of existing buildings [3].

In this paper, a first holonic computing structure based on CPS technology is developed for indoor comfort management as well as medium- and long-term refurbishment processes of a large public building. The diagnosis is

*Corresponding author: Author email: 1.messi@ staff.univpm.it 
based on the measurement of the effectiveness of every device intended as a unit of the system of systems. During simulations, an overall throughput effectiveness (OTE) metrics measures the subsystems' performances and drives refurbishment design for their enhancement [4]. In fact, suggestions, history and lessons learnt from the OTE evolutions are re-directed to a BIM model to support decision making for the improvement of the whole building performance and design.

This paper is organised as follows. Section 2 provides a literature review of the holonic approach that was adopted in the present research. Section 3 describes the case research methodology. Section 4 provides a description of the case study. Section 5 shows the simulation results. Section 6 is devoted to conclusions.

\section{Literature review}

The holonic concept, which is the basis of holonic management systems, was introduced in 1967 by Koestler [5] to explain the evolution of biological and social systems. Likewise, in the real world, where almost everything is at the same time a part and a whole, each holon can be part of another holon [6]. In fact, the word holon is the combination of "holos", which in Greek means "whole", and the suffix "on", which suggests a part [7], [8], [9]. In the manufacturing field, holons are autonomous and cooperative building blocks, since they can both control the executions of their own strategies and develop mutually acceptable plans [6]. Furthermore, holons consist of an information-processing part and often a physical processing part [6], [7], [8]. The former is responsible for high-level decision making, collaborating and negotiating with humans and other holons, while the latter is a representative of its linked physical component and responsible for transferring decisions and instructions to it [7]. According to Koestler, a holonic system or holarchy is then a hierarchy of self-regulating holons that function (i) as autonomous wholes in supra-ordination to their parts, (ii) as dependent parts in subordination to control at higher levels, and (iii) in coordination with their local environment [6], [5], [9]. Therefore, holonic architecture combines high and predictable performance, which distinguishes hierarchical systems, with the robustness against disturbances and the agility typical of heterarchical systems [8]. In this way, systems' resilience is guaranteed.

The agent, which in latin is "a person who acts", is a software-based decision making unit embedded with internal knowledge. Unlike holons, no such separation of physical and information processing parts exists in agents' structure. Furthermore, whereas holons can themselves be made up of other autonomous holons, agents do not immediately apply the recursive architecture [6], [7]. A multi-agent system is made up of two or more related agents [6], [9].

Cyber-physical systems, in the manufacturing field, are systems of collaborating computational entities which are in intensive connection with the surrounding physical world [10]. The interaction between physical and cyber elements is of key importance to the purpose of this paper. As a matter of fact, cyber-physical systems, similarly to holons, consist of a cyber part and a physical part. This shared feature makes holonic paradigm a suitable approach for constructing and modelling a CPS system in the form of a holarchy. Therefore, on the one hand, a CPS system permits bidirectional coordination of virtual and physical levels and, on the other, the holarchy, with its flexibility, guarantees evolutionary self-organisation or, in other words, resilience [7]. Moreover, CPS systems provide an opportunity for changes in the physical structure to be captured and reflected in the virtual model. Conversely, changes in the virtual model can be communicated to sensors embedded in the physical world [11], [12]. To implement these concepts in real world applications, agents are key enablers, since they act as decision-making and communication entities with agents embedded in other holons and also humans [7], [8]. Holonic management systems, which have been successfully applied in the manufacturing field, can constitute a novel technology to tackle unforeseen scenario variations. Indeed, the autonomy and cooperation of their elementary units, the holons, make it possible to avoid the rigid structure of hierarchical systems and therefore respond quickly to disturbances [6].

\section{Research methodology}

\subsection{System architecture}

The holonic computing structure developed in this paper involves three development environments, Matlab $^{\circledR} /$ Simulink $^{\circledR}$, SQL and Revit ${ }^{\circledR}$ (see Figure 1). 


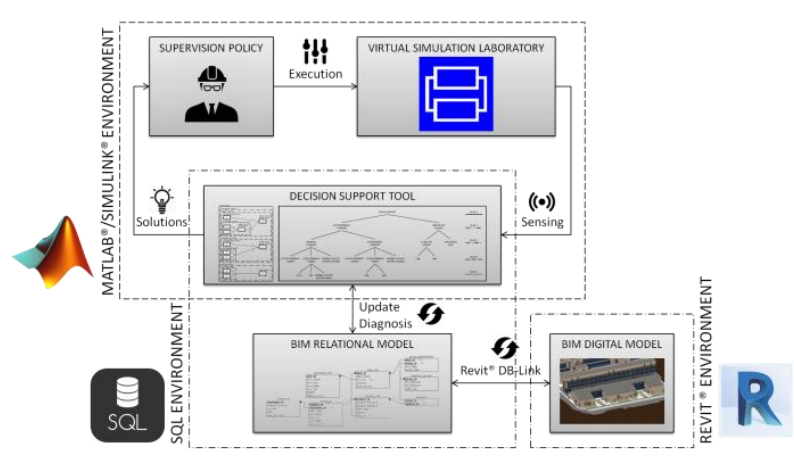

Figure 1. The architecture of the developed holonic computing structure based on CPS technology.

The Revit ${ }^{\circledR}$ environment concerns the BIM Digital Model (BIM DM), as the interface of one of the numerous BIM softwares available on the market, such as Autodesk ${ }^{\circledR}$ Revit $^{\circledR}$. The Matlab ${ }^{\circledR}$ and SQL environments share the Decision Support Tool (DST), which has the function to assess the system of systems' effectiveness and suggest a list of possible corrective actions. In details, the distributed performance metrics, inherited from the manufacturing field, defines the overall factory effectiveness (OFE), the overall throughput effectiveness (OTE) and the overall equipment effectiveness (OEE). These parameters, whose values are between 0 and 1 , are effectiveness indexes referring respectively to the highest level, intermediate levels and the lowest levels of a system's tree (see Figure 2.b). Once the cells' OEE values are determined according to [13] and [4], every subsystem's OTE values are obtained following the formulas in [14]. Afterwards, by means of the Event-Condition-Action (ECA) calculation model described in [4], the DST provides, for each iteration, a list of actions towards improvement of system's performance. Note that the system's scheme (see Figure 2.a) explains its semantics exploiting the analogy with a manufacturing production line [14], [15] and could be defined as the closest representation to the humans' way of thinking. Conversely, the system's tree is the closest representation to the computing structure (see Figure 2.b).

a.

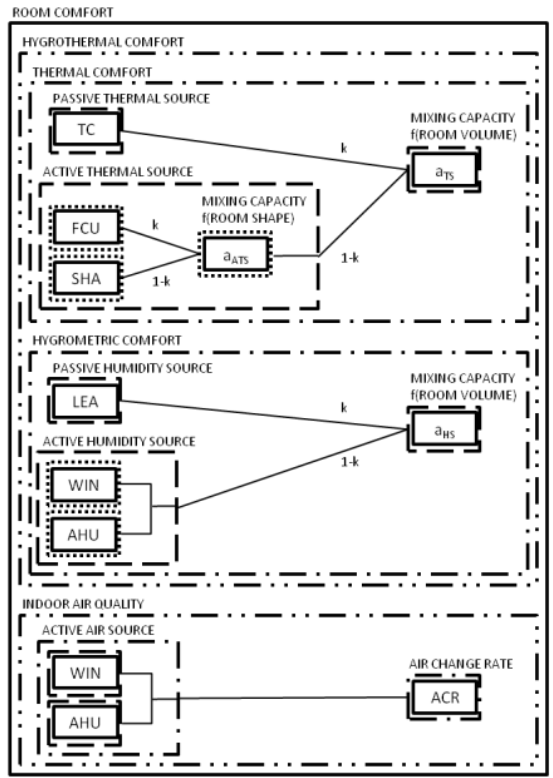

b.

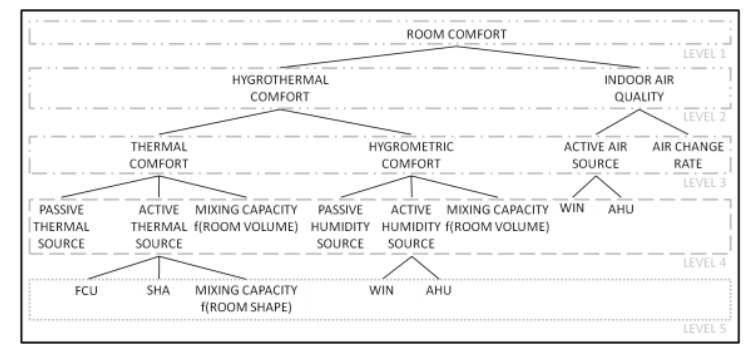

Figure 2. a. System's scheme and b. system's tree developed for the case study.

The Matlab ${ }^{\circledR}$ environment consists of the Virtual Simulation Laboratory (VSL) and Supervision Policy (SP), beside the DST described above. The Virtual Simulation Laboratory is in charge of replacing and emulating the real building by using a detailed building model. This model was developed in the Dymola ${ }^{\circledR}$ programming environment, which is based on the Modelica ${ }^{\circledR}$ Language. The building model used in this work was built upon the open-source Modelica ${ }^{\circledR}$ "Buildings" library [16] and it has the level of detail that is necessary to analyse the behaviour of each 
device and sub-system belonging to the building. The measures taken from the VSL provide feedback (delayed by 1 step in order to be realistic) for the decision support tool. The DST evaluates and updates the OEE of each cell by means of SQL queries, then it updates the OTE in all the system's tree and suggests a list of possible actions to the Supervision Policy. Among the actions suggested by the DST, the Supervision Policy selects and applies the one to be carried out in the Virtual Simulation Laboratory based on some internal logic/intelligence. As if sensors and actuators are distributed all around the building, the applied methodology makes it possible to monitor trends of physical variables and track inputs (normalised between 0 and 1) of corrective actions (see Figure 3).

a.
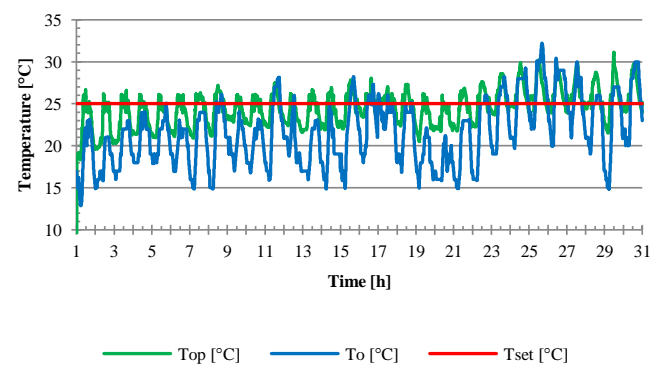

b.

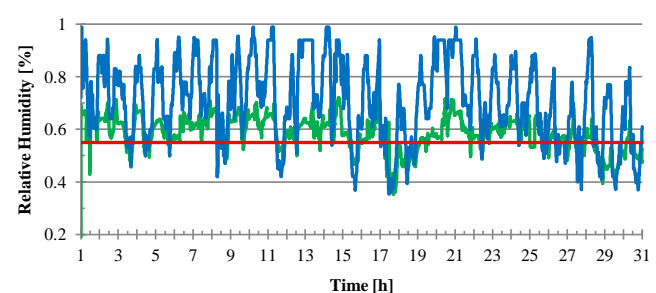

$\longrightarrow$ RHi [\%] $\longrightarrow$ RHo [\%] $\longrightarrow$ RHset [\%]

c.

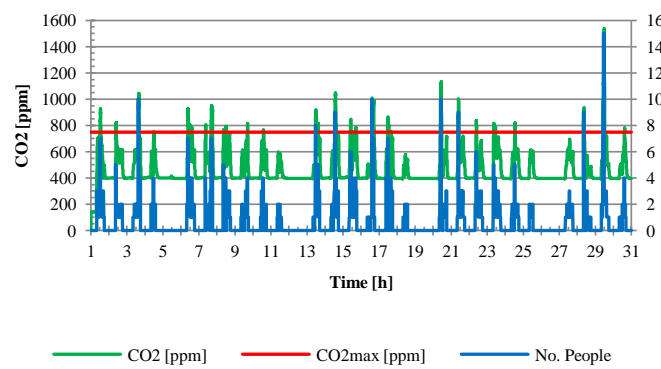

d.

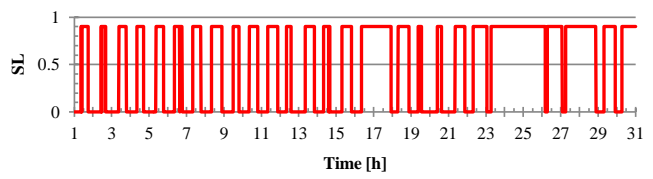

e.

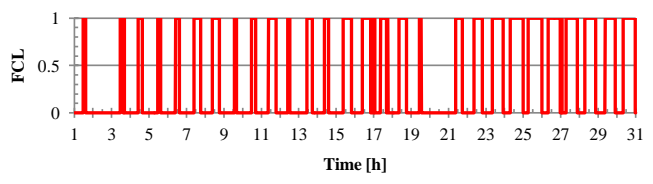

f.

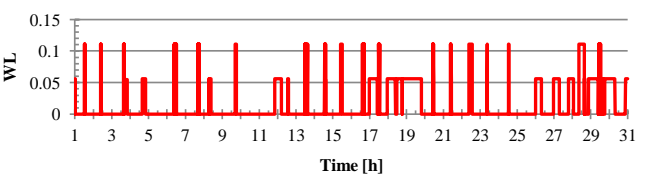

Figure 3. Operation management results for the month of June. Trends of a. temperature, b. relative humidity, c. $\mathrm{CO}_{2}$ concentration vs number of people inside room no. 90, d. shading level (SL), e. fan coil level (FCL) and f. window level (WL).

Finally the SQL environment involves, in addition to the DST, the BIM Relational Model (BIM RM, see Section 3.2), i.e. a relational database that acts as a bridge between the DST and BIM DM and has a double function. The first function is to update the DST when the BIM DM changes. The second one is to store effectiveness data received from the DST to run building's diagnoses. The BIM RM and BIM DM exchange data in both directions, thanks to the Revit ${ }^{\circledR}$ DB-Link plug-in. In this way, the SQL and the Revit ${ }^{\circledR}$ environments are connected.

The holonic computing structure developed and implemented by integrating Simulink ${ }^{\circledR}$, SQL and Revit ${ }^{\circledR}$ environments makes it possible to carry out any type of desired simulations away from the site.

\subsection{BIM Relational Model}

In this paper the BIM Relational Model and BIM Digital Model are two sides of the same coin, the practical and the formal side, respectively. The BIM DM of the building under analysis was developed using Autodesk ${ }^{\circledR}$ Revit $^{\circledR}$ 
and then translated into its congenital relational structure, namely the BIM RM. Hence, the BIM Model works as a repository of any types of data that belong to the building analysed.

The connection BIM RM-DST, as mentioned, provides the opportunity to define and update the scheme of the DST after changes to the building. In addition, the same link provides, in the other direction, the possibility of selfdiagnosis of the holonic management system developed. Actually, the BIM model becomes a repository of the facility history or of the potential actions of improvement concerning the building. Indirectly, a bi-directional communication channel is set up, i.e. a learning phase of the VSL from the BIM repository and the storage of realtime data from VSL into the BIM model.

In order for this to happen, the relational potential of the BIM has to be fully expressed. The underlying BIM representation of the information can be leveraged and further extended to create a mapping between a relational database. Note that the full Relational Model (RM) is intended in the sense described in [17]. In the RM everything is a relational variable (relvar). Tables, attributes and database schemas cannot usually be operated relationally. In current SQL-based database management systems (DBMS), these operations are implemented with non-standard host language proprietary extensions for the specific DBMS implementation. By a homomorphic mapping between the BIM and its relational representation, we obtain the opportunity to develop new structured types that make it possible to record relational information and data. For example, in a BIM entity, it is possible to completely record the real-time history of parts of the building equipment as obtained from sensors. Moreover, it is also possible to record a tracking of the BIM structural changes over time. With data mining, knowledge extraction and representation techniques, some information can be grown upon, enriched, and a reasoning system can be integrated into the relational model of the building. This allows us to make BIM the core of short-term control and mediumand long-term design evolutions and adaptations on the building endowed with intelligence.

As a first experiment, the best available technology on DBMS has been used as a proof of concept. In order to interact bi-directionally with the BIM, the building digital model has been mapped to an SQL Server ${ }^{\mathbb{B}}$ DBMS using the Revit ${ }^{\circledR}$ DB-Link plug-in (see Figure 4). It permits the flow of information between Autodesk ${ }^{\circledR}$ Revit $^{\circledR}$ and the DBMS in both directions. In this way BIM is updated with changes applied from the reasoner or the controller, and receives the real-time data from the virtual or physical models or the sensors. A workaround to the limited relational possibilities has been temporary created by extending some of the basic elementary BIM attributes with a numeric type that creates a primary key to some relations that can store real-time data tables or even a complete (nested) database schema.

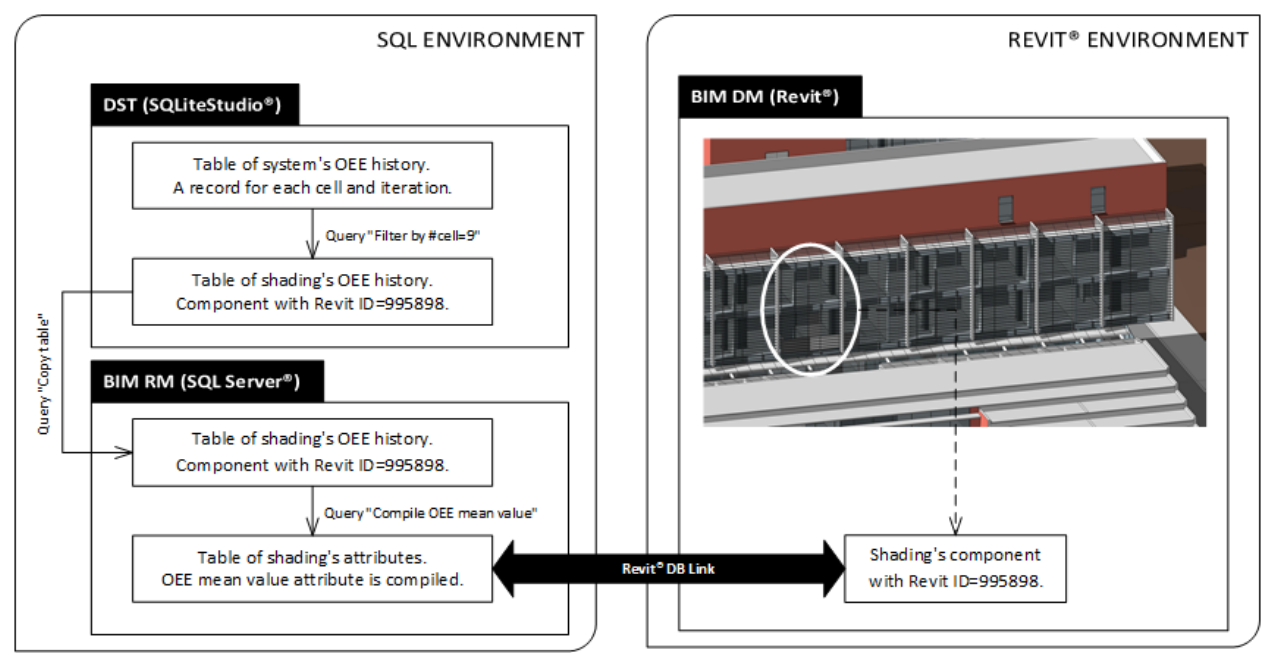

Figure 4. DST-BIM RM and BIM RM-BIM DM connections.

System's OEE history from DST, stored inside SQL Environment in a SQLiteStudio ${ }^{\circledR}$ DBMS, can be processed by queries (see Table 1) in order to make diagnoses (see Figure 4). As an example, cell 9's OEE values can be copied from the whole history into the table "ID_995898" (see "Filter by \#cell=9" query in Table 1 and Figure 5.a.) and, once exported in SQL format, re-directed into SQL Server ${ }^{\circledR}$ DBMS (see "Copy table" query in Table 1). Afterward, shading's OEE mean value, updated in real-time for each iteration, can be stored inside BIM RM, filling the specific attribute inside table "GenericModels" (see "Compile OEE mean value" query in Table 1 and Figure 
5.b.). Note that the shading's component in front of the case study room corresponds to cell 9 of the system of systems (i.e. "SHA" in Figure 2.a. and b.) and to the Revit element whose ID is 995898. Finally, the shading's OEE mean value can be re-directed to the BIM DM using Revit ${ }^{\circledR}$ DB-Link plug-in and displayed inside Autodesk ${ }^{\circledR}$ Revit $^{\circledR}$ as a shading's parameter (see Figure 6.a.).

Table 1. Queries to process and link data in SQL Environment.

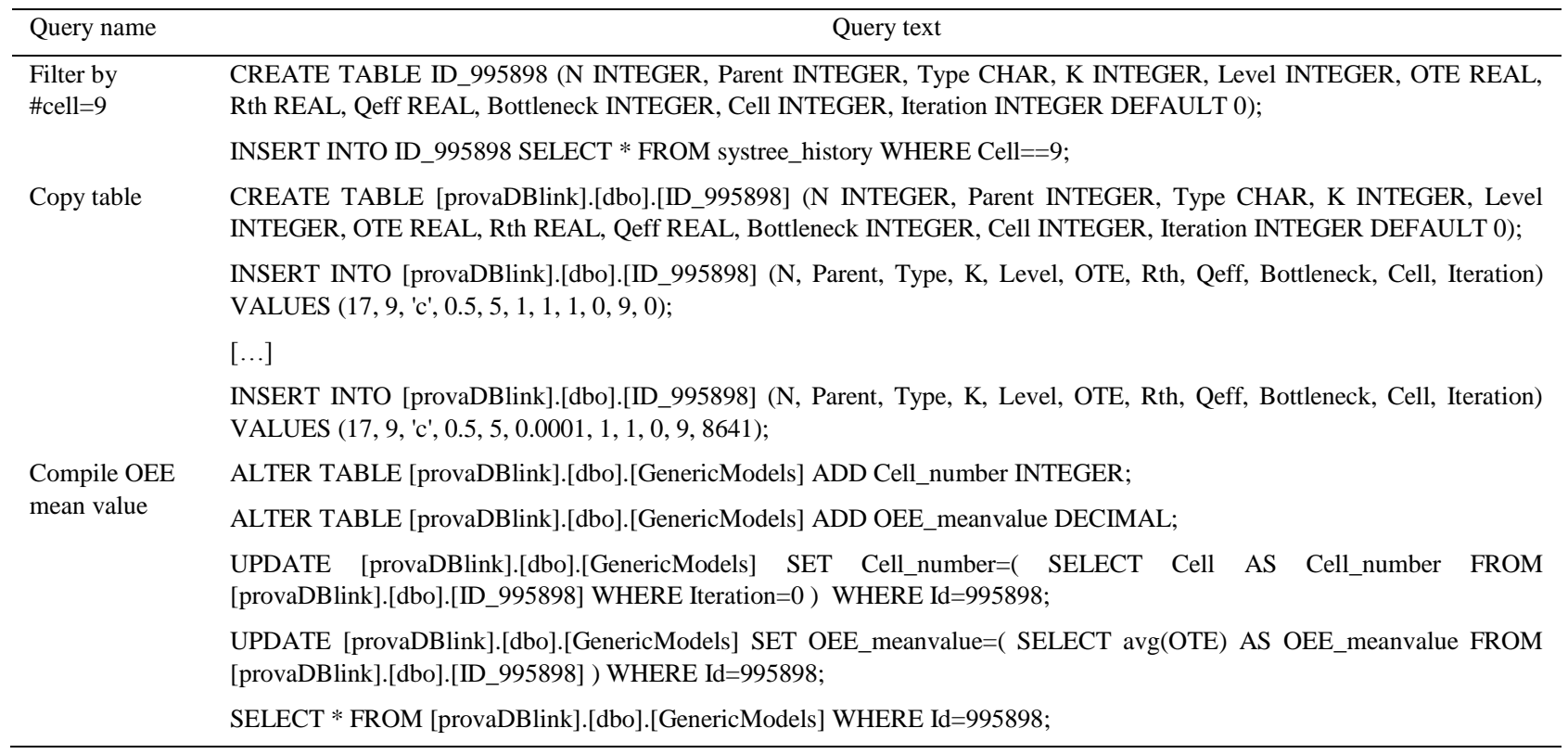

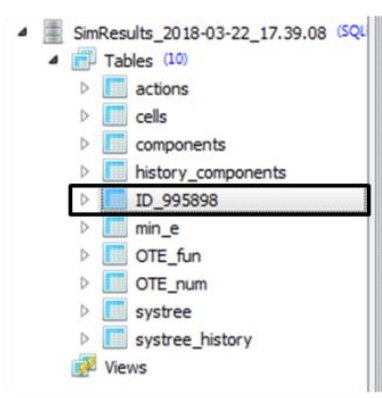

\begin{tabular}{||l||l|}
\hline 1 \\
\hline 2 \\
\hline 3 \\
\hline 4 \\
\hline 5 & \\
\hline 6 & \\
\hline 7 & \\
\hline 8 & \\
\hline 9 & \\
\hline 10 \\
\hline 11 \\
\hline 12 \\
\hline 13 \\
\hline
\end{tabular}

\begin{tabular}{|r|r|r|r|} 
N & Parent & Type & \multicolumn{1}{l}{$K$} \\
\hline 17 & $9 \mathrm{C}$ & 0.5 \\
\hline 17 & $9 \mathrm{C}$ & 0.5 \\
\hline 17 & $9 \mathrm{C}$ & 0.5 \\
\hline 17 & $9 \mathrm{C}$ & 0.5 \\
\hline 17 & $9 \mathrm{C}$ & 0.5 \\
\hline 17 & $9 \mathrm{C}$ & 0.5 \\
\hline 17 & $9 \mathrm{C}$ & 0.5 \\
\hline 17 & $9 \mathrm{C}$ & 0.5 \\
\hline 17 & $9 \mathrm{C}$ & 0.5 \\
\hline 17 & $9 \mathrm{C}$ & 0.5 \\
\hline 17 & $9 \mathrm{C}$ & 0.5 \\
\hline 17 & $9 \mathrm{C}$ & 0.5 \\
\hline 17 & $9 \mathrm{C}$ & 0.5 \\
\hline
\end{tabular}

\begin{tabular}{rr|r|}
\cline { 3 - 3 }$K$ & Level & \multicolumn{1}{|c|}{ OTE } \\
\hline 0.5 & 5 & 1 \\
\hline 0.5 & 5 & 0.0001 \\
\hline 0.5 & 5 & 0.38079 \\
\hline 0.5 & 5 & 1 \\
\hline 0.5 & 5 & 1 \\
\hline 0.5 & 5 & 1 \\
\hline 0.5 & 5 & 0.90697 \\
\hline 0.5 & 5 & 0.70455 \\
\hline 0.5 & 5 & 0.52988 \\
\hline 0.5 & 5 & 0.38543 \\
\hline 0.5 & 5 & 0.27056 \\
\hline 0.5 & 5 & 0.18314 \\
\hline 0.5 & 5 & 0.11989 \\
\hline
\end{tabular}

\begin{tabular}{|c|c|c|c|c|}
\hline Rth & Qeff & Bottleneck & Cell & Iteration \\
\hline 1 & 1 & 0 & 9 & 0 \\
\hline 1 & 1 & 0 & 9 & 1 \\
\hline 1 & 1 & 0 & 9 & 2 \\
\hline 1 & 1 & 0 & 9 & 3 \\
\hline 1 & 1 & 0 & 9 & 4 \\
\hline 1 & 1 & 0 & 9 & 5 \\
\hline 1 & 1 & 0 & 9 & 6 \\
\hline 1 & 1 & 0 & 9 & 7 \\
\hline 1 & 1 & 0 & 9 & 8 \\
\hline 1 & 1 & 0 & 9 & 9 \\
\hline 1 & 1 & 0 & 9 & 10 \\
\hline 1 & 1 & 0 & 9 & 11 \\
\hline 1 & 1 & 0 & 9 & 12 \\
\hline
\end{tabular}
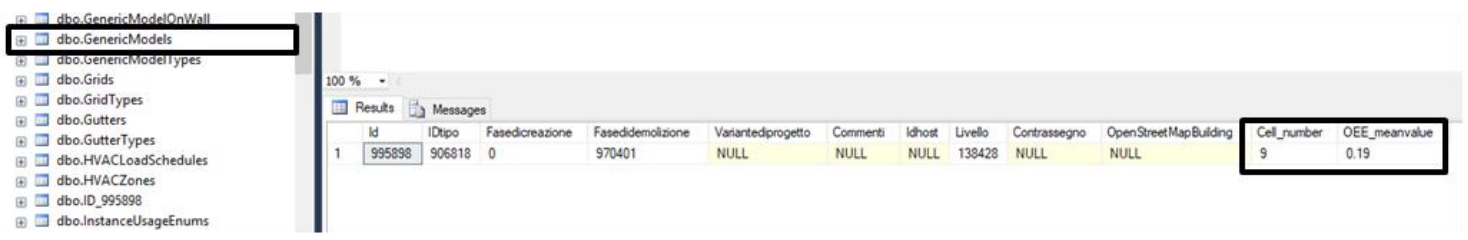

Figure 5. a. Results of "Filter by \#cell=9" query applied inside SQLiteStudio ${ }^{\circledR}$ workspace (DST) and b. "Copy table" and "Compile OEE mean value" queries applied inside SQL Server ${ }^{\circledR}$ (BIM RM).

\section{Case study}

Eustachio building is the location of the Faculty of Medicine of the Polytechnic University of Marche, located in Ancona, Italy. This is a large and multi-purpose building composed by two main blocks, that create a clear division between the main fronts: the north and the south ones. The heating system is a two-pipe type and the air-handling 
system serves separately the north and the south fronts. Consequently, the building has some symptomatic discomfort problems as, for example, too high temperatures during winter, too low temperatures during summer and mid-season temperatures out of control.

In this paper, the focus is on one office room (i.e. room no. 90), located on the third level of the South front and used as an office (Figure 6.b.). Its net surface is approximately $19 \mathrm{~m}^{2}$ and the three-modules window is about $7 \mathrm{~m}^{2}$ large, one of which is operable. The room no. 90's air handling unit causes just air recirculation, since the humidifier is not working. The fan coil unit is a FC200 type and, for the purpose of the paper, only its cooling function in the summer season is considered. In addition, a shading system is also included. The application to this room has been used as a proof of concept for further simulations to the whole building. The described methodology (see Section 3) makes it possible to diagnose quickly the causes of building's shortcomings in term of indoor climate comfort and plan future refurbishment.

a.

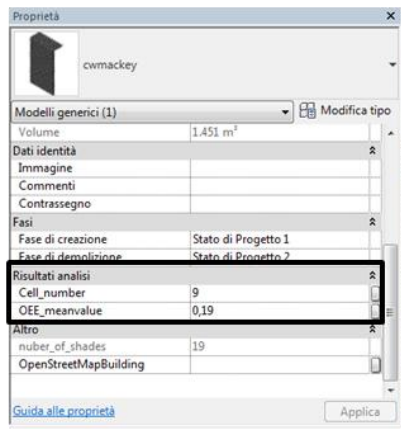

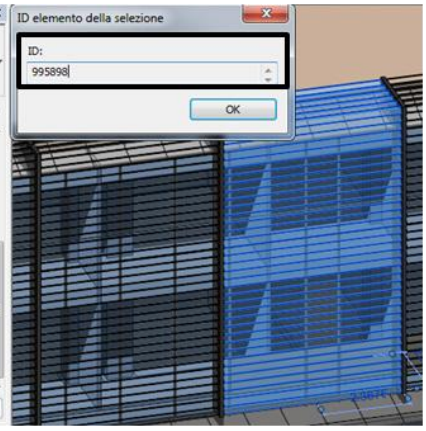

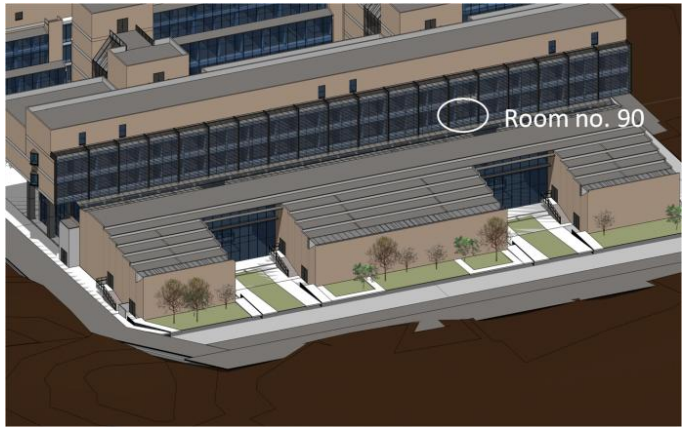

Figure 6. a. The shading's OEE mean value displayed inside Autodesk ${ }^{\circledR}$ Revit $^{\circledR}$ as a shading's parameter and a. the room no. 90 in a 3D view of the Eustachio building's BIM DM.

\section{Simulations results}

The holonic management system, described in this paper is experienced for the month of June 2016. In this period, weather data define really dynamic boundary conditions able to strongly urge the system. The simulations for this representative scenario aim to prove the system's ability to perform not only short-term operation management in real-time, but also diagnoses of building with regard to medium- and long-term refurbishment. In fact, the holonic management system makes it possible to carry out diagnoses on buildings by focusing on the system of systems' and cells' effectiveness mean value. In details, BIM RM can:

- $\quad$ store system of systems' time data, such as OTE/OEE time values, creating a repository of the facility history;

- $\quad$ store (see Figure 5.b.) and re-direct their mean values, which are continuously updated according to the last iteration, to the BIM DM (see Figure 6.a.) in order to visualise them inside Revit ${ }^{\circledR}$ environment (e.g. during refurbishment design of building).

Low monthly mean values of OTE and OEE highlight entities that cannot pursue the assigned target towards room comfort. Figure 7 shows OEE monthly mean values (June 2016) for the system's cells (the leaves of the tree, see Figure 2.b.). The histograms point out the highest effectiveness of Indoor Air Quality sub-system. In fact, the room assumed as case study has a good air change rate $\left(\mathrm{OEE}_{\mathrm{ACR}}=0.89\right)$ and window $\left(\mathrm{OEE}_{\mathrm{WIN}(\mathrm{IAQ})}=0.76\right)$ and air handling unit $\left(\mathrm{OEE}_{\mathrm{AHU}(\mathrm{IAQ})}=0.86\right)$ ensure a satisfactory ventilation in June. Whereas, the room's external partitions are not effective in terms of thermal conduction $\left(\mathrm{OEE}_{\mathrm{TC}}=0.15\right)$ for indoor thermal comfort, since they are made of glass and metal. The shading $\left(\mathrm{OEE}_{\mathrm{SHA}}=0.19\right)$ and fan coil unit $\left(\mathrm{OEE}_{\mathrm{FCU}}=0.31\right)$ show possibility of improvement, since the former can be extended to the whole glass façade (both the transparent and the glazed part) and the latter can be boosted up. Results about hygrometric comfort point out how the window $\left(\mathrm{OEE}_{\mathrm{WIN}(\mathrm{HC})}=0.11\right)$ and air handling unit $\left(\mathrm{OEE}_{\mathrm{AHU}(\mathrm{HC})}=0.17\right)$ does not ensure a good enough contribution to optimal indoor relative humidity and room's external partitions are not effective, because of air leakage $\left(\mathrm{OEE}_{\mathrm{LEA}}=0.22\right)$. 


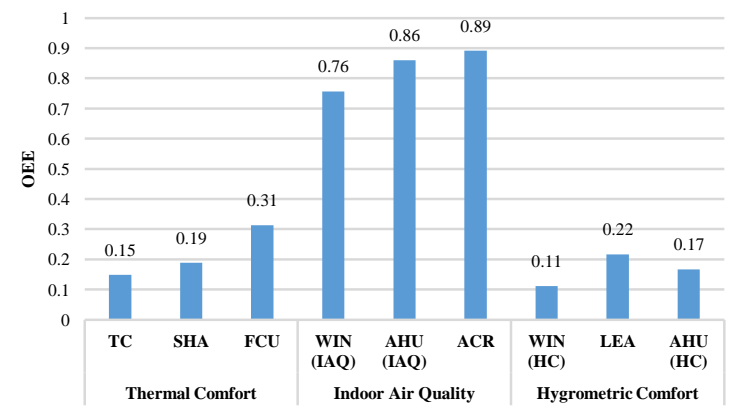

Figure 7. OEE monthly mean values (June 2016).

\section{Conclusions}

The holonic computing structure, which involves Matlab ${ }^{\circledR} /$ Simulink $^{\circledR}$, SQL and Revit ${ }^{\circledR}$ development environments, is experienced in a room used as an office. The latter has been used as a proof of concept for further simulations to the whole building. The methodology described in this paper makes it possible to diagnose quickly the causes of building's shortcomings in term of indoor climate comfort and plan future refurbishment. Furthermore, the BIM RM has been experienced as a repository where OEE/OTE effectiveness values of system of systems are stored. Finally, but not least, these values are re-directed to the BIM DM and displayed inside Autodesk ${ }^{\circledR}$ Revit $^{\circledR}$ as element's parameters.

\section{References}

[1] Rebekka Volk, Julian Stengel, Frank Schultmann. Building Information Modeling (BIM) for existing buildings - Literature review and future needs. Automation in Construction, 38, 2014, p. 109-127.

[2] Teicholz Eastman, Liston Sacks. BIM Handbook - a guide to building information modeling for owners, managers, designers, engineers and contractors, Aufl, 2, Wiley, Hoboken, 2011.

[3] Silvana Bruno, Mariella De Fino, Fabio Fatiguso. Historic Building Information Modelling: performance assessment for diagnosis-aided information modelling and management. Automation in Construction, 86, 2018, p. 256-276.

[4] Andrea Bonci, Massimiliano Pirani, Sauro Longhi, Robotics 4.0: Performance Improvement Made Easy, Proceedings of the 22nd IEEE, International Conference on Emerging Technologies and Factory Automation (ETFA), 2017.

[5] Koestler A., The Gost in the Machine. The Macmillan Company, Hutchinson, 1967.

[6] Paul Valckenaers, Henrik Van Brussel, Design for the Unexpected, From Holonic Manufacturing Systems towards a Humane Machatronics Society, Butterworth-Heinemann, 2016.

[7] Lihui Wang, Azadeh Haghighi, Combined strength of holons, agents and function blocks in cyber-physical systems, Elsevier, Journal of Manufacturing Systems, 2015.

[8] Paul Verstraete, Bart Saint Germain, Karuna Hadeli, Paul Valckenaers, Henrik Van Brussel, On applying the PROSA reference architecture in multi-agent manufacturing control applications, Multiagent Systems and Software Architecture, Proceedings of the Special Track at Net.ObjectDays, 2006.

[9] Adriana Giret, Vicente Botti, Holons and Agents, Kluwer Academic Publishers, Journal of Intelligent Manufacturing, 2004.

[10]L. Monostori, B.Kádár, T.Bauernhansl, S.Kondoh, S.Kumara, G.Reinhart, O.Sauer, G.Schuh, W.Sihn, K.Ueda Cyber-physical systems in manufacturing, CIRP Annals - Manifacturing Technology; 2016.

[11]Xiao Yuan, Chimay J. Anuba, M. Kevin Parfitt, Cyber-physical systems for temporary structure monitoring, Elsevier, Automation in Construction, 2015.

[12] Abiola Akanmu, Chimay J. Anubia, Cyber-physical systems integration of building information models and the physical construction, Emerald Insight, Engineering, Construction and Architectural Management, 2015.

[13] K. M. N. Muthiah, and S. H. Huang. "Overall throughput effectiveness (OTE) metric for factory-level performance monitoring and bottleneck detection”. Int. J. Prod. Res, vol. 45, no. 20, pp 4753-4769, 2007.

[14] M. Pirani, A. Bonci, S. Longhi, S., A scalable production efficiency tool for the robotic cloud in the fractal factory. In Industrial Electronics Society, Annual Conference of the IEEE, 2016.

[15] Stadnicka D., Bonci A., Pirani M. and Longhi S. Information management and decision making supported by an intelligence system in kitchen fronts control process. In Proc. of the First Int. Conf. On Intelligent Sys. in Production Eng. and Maintenance ISPEM 2017.

[16]Wetter, M., Zuo, W., Nouidui, T. S., \& Pang, X.. Modelica ${ }^{\circledR}$ buildings library. Journal of Building Performance Simulation, 2014, 7.4: 253270.

[17]Hugh Darwen. An Introduction to Relational Database Theory. Bookboon, 2009. 